\title{
- APLICATIVO CLUBE ZOOM E SUA CONTRIBUIÇÃO À COMUNICAÇÃO: LAZER E TURISMO NA CIDADE DE PARNAÍBA/PIAUÍ
}

\author{
JOSÉ MARIA ALVES DA CUNHA \\ Universidade Federal do Piauí \\ Parnaíba,Piauí,Brasil \\ E-mail:
}

JOSÉ GERALDO DA SILVEIRA JÚNIOR Universidade Federal do Piauí Parnaíba,Piauí,Brasil

E-mail:

ANDRÉ RIANI COSTA PERINOTTO Universidade Federal do Piauí Parnaíba,Piauí,Brasil

E-mail: 
O APLICATIVO CLUBE ZOOM E SUA CONTRIBUIÇÃO À COMUNICAÇÃO: LAZER E TURISMO NA CIDADE DE PARNAÍBA/PIAUÍ

Resumo: $O$ trabalho aborda o uso de aplicativos para smartphones e tablets no turismo. O objetivo central é analisar o aplicativo Clube Zoom como ferramenta de lazer e turismo na cidade de Parnaíba, Piauí. Utilizou-se a pesquisa bibliográfica, a aplicação de questionários e a entrevista como métodos e técnicas. Constatou-se a funcionalidade e eficiência do Clube Zoom, porém requer mais aprimoramento e maior divulgação para a sua consolidação.

Palavras-chave: Clube Zoom; Dispositivos móveis; Lazer e turismo; Tecnologia da Informação e Comunicação

EL APLICATIVO CLUBE ZOOM Y SU CONTRIBUCIÓN A LA COMUNICACIÓN: OCIO Y TURISMO EN LA CIUDAD DE PARNAÍBA/PIAUÍ

Resumen: En trabajo discute la utilización de aplicativos para smartphones y tablets en el turismo. El objetivo central es analizar el aplicativo Club Zoom como herramienta de ocio y turismo en la ciudad de Parnaíba, Piauí. Se utilizó la investigación bibliográfica, la aplicación de encuestas y la entrevista como métodos y técnicas. Se comprobó la funcionalidad y eficiencia del Club Zoom, pero se necesita más mejoramiento y mayor divulgación para su consolidación.

Palabras clave: Clube Zoom; Dispositivos móviles; Ocio y Turismo; Tecnología de la información y comunicación

\section{CLUBE ZOOM APPLICATION AND ITS CONTRIBUTION TO COMMUNICATION: LEISURE AND TOURISM IN THE CITY OF PARNAIBA/PIAUÍ}

Abstract: This paper approaches the use of smartphone and tablet applications on tourism. The main objective is to analyze the application Clube Zoom as a tool for leisure and tourism in the city of Parnaíba, Piauí. A bibliographical research, the use of surveys and an interview were used as methods and techniques. The functionality and efficacy of Clube Zoom could be seen, however more enhancement and broadcast is required for its consolidation.

Key words: Clube Zoom; Mobile Devices; Leisure and Tourism; Communication and Information Technology. 


\section{INTRODUÇÃO}

A Internet é uma ferramenta tecnológica utilizada em quase todos os setores da economia, tendo aspectos relevantes no que diz respeito à diminuição de custos, como também na redução dos processos trabalhistas. Flecha e Da Costa (2004) destacam que no setor de lazer e turismo, a Internet incorpora diversas funcionalidades altamente eficientes, causando inserções positivas quanto à execução e o consumo da atividade.

Para Nunes e Mayer (2012), a informação é uma peça fundamental no turismo. Associado a isso, há a necessidade do viajante em estar conectado por meio de diferentes dispositivos móveis, isso, certamente, cria oportunidades na melhoria dos serviços turísticos das destinações visitadas.

Segundo Cruz, Mota e Perinotto (2012), o acesso a informações de uma destinação turística torna-se um fator decisório numa viagem. Este aspecto proporciona ao viajante a oportunidade de ele mesmo montar e planejar sua viagem, sem a necessidade de se deslocar para espaços físicos de agências de turismo ou contratar os serviços de um agente de viagens, realizando todos os procedimentos pela rede mundial de computadores.

Fora desta análise, mas com paridades quanto ao assunto, Trigo (2000, p. 58) destaca que "As mudanças estão acontecendo nas sociedades contemporâneas de uma forma rápida e profunda". Continua, dizendo: "Os avanços tecnológicos surgem das mais diversas necessidades e, repentinamente, são apropriados, parcial ou totalmente, pela sociedade" (ibid., p. 59). A contribuição de Trigo advém da década de 1990 e os resultados são compatíveis à atualidade, demonstrando como se efetua o processo de desenvolvimento da sociedade pós-industrial com o uso da tecnologia para informação e comunicação, em parte direcionada ao lazer e turismo.

Portanto, o presente artigo tem o objetivo principal de analisar o aplicativo Clube Zoom como ferramenta de informação e comunicação no lazer e turismo na cidade de Parnaíba, Piauí. Além disso, o trabalho busca descrever o uso intensivo da Internet pelo setor de turismo com vistas ao seu desenvolvimento enquanto atividade socioeconômica, a qual necessita da Internet para o seu aperfeiçoamento.

\section{TURISMO E INTERNET}

O turismo é uma atividade socioeconômica e seu crescimento acentuado se 
deu após a Revolução Industrial com a introdução de novas ferramentas tecnológicas, responsáveis por transformações ocorridas na função e ordem mundial e que hoje são fundamentais à execução da atividade (CACHO; AZEVEDO, 2010).

Pérez (2009) considera a atividade do turismo um tanto quanto complexa, pois à sua execução, inúmeros processos são integrados, colocando-a como um importante setor da economia para diversos países. Pelo dinamismo e inter-relacionamento com outras atividades, o turismo demanda muitos conhecimentos, fundamentados na tecnologia, marketing, meio ambiente, sociedade, cultura, política, dentre várias outras condicionantes.

Um dos primeiros setores da economia a utilizar a Internet em transações eletrônicas foi o turismo, isso se deu com a introdução dos sistemas de reservas eletrônicas das companhias aéreas a partir da década de 1960 (LUCCA FILHO, 2005). De acordo com Bettoni (2009), é a partir da década de 1990 que os novos grupos de turistas surgem, na sua grande maioria na busca por destinos até então desconhecidos. Com isso, subtende-se que o desejo dos turistas, geralmente, é o de estar no comando da viagem, não como desbravadores, mas como conhecedores e planejadores. Muitos destes grupos fazem uso das ferramentas tecnológicas, possibilitando ao viajante o planejamento de sua própria viagem, porém deve-se saber fazer o uso correto destas ferramentas tecnológicas.

O processo de desenvolvimento tecnológico passa por constantes meIhorias, otimizando o acesso à comunicação e a informação nos dias atuais. Neste sentido, Bjerg, Larrea e Pachiana (2012, p. 3) afirmam que:

Los efectos de las nuevas tecnologías tienen repercusiones en distintos ámbitos de la vida humana, como ser la economía, el empleo, la forma de producción, la educación, entre otros. La verdadera transformación tecnológica implica disponer las nuevas tecnologías como recurso, pero más aun, en la posibilidad de gestionarlas y aplicarlas, lo que da como resultado diferentes realidades territoriales.

Desse modo, Biz (2009) coloca que o uso da Tecnologia da Informação e Comunicação (TIC) tem papel importante no desenvolvimento da sociedade contemporânea, implicando em melhorias nos mais diversos setores da economia, com relevantes resultados no turismo.

Flecha e Da Costa (2004) relatam sobre a interação e o mercado dinâmico do turismo em volta das tendências cibernéticas e do acentuado uso de web sites como um meio para o marketing e a transação de produtos e 
serviços no turismo. O comportamento do mercado nos últimos anos indica um aumento gradativo do uso dessas ferramentas tecnológicas, sendo o turismo o setor com um grande aproveitamento dessa expansão. Assim, Silva e Mendes Filho (2013) destacam que a utilização das TIC's estabelece parâmetros que exprimem um novo sentido das relações sociais e turísticas, comprovando a interdependência de um pelo o outro.

Destarte, O'Connor (2001) salienta que para a contínua ascensão do turismo a informação torna-se fundamental, uma vez que sem ela o setor não funcionaria, nem tinha como se expandir, posto que o consumidor atual necessita de informação suficiente para a tomada de decisões quanto ao que visitar, onde se hospedar, qual o modal de transporte, dentre outros questionamentos que se faz pertinente no planejamento de uma viagem.

De acordo com Cacho e Azevedo (2010), essa necessidade por informações advém daqueles novos grupos de turistas supramencionados, os quais querem vivenciar a viagem antes mesmo de sair de casa. Isto só é possível graças à introdução e ao desenvolvimento de uma série de experimentos ligados à informática, que vão desde a criação de softwares específicos até aos atuais e populares aplicativos de smartphones e tablets, provando ser ferrenho o uso das TIC's pelo novo perfil de viajante do século XXI.

Para Bjerg, Larrea e Pachiana (2012) as TIC's constituem-se de ferramentas que admitem manipular informações, permitindo tratamento e transmissão através da Internet, sobretudo, por meio de outros dispositivos e canais de telecomunicações. Todavia, por se tratar de produtos intangíveis, os consumidores do turismo devem receber informações precisas, verídicas e confiáveis, sem que haja manipulação suficiente para distorcer o produto real do comercializado, visando assegurar ao consumidor quanto à compra de um produto que nunca será consumido instantaneamente.

O'Connor (2001) atenua sobre a necessidade por informações ligadas ao turismo pela intangibilidade dos produtos e por esta ser uma atividade que vende desejos. Estes fatores estimulam o consumidor a buscar incansavelmente o maior número de informações acerca do destino, seguindo uma tendência lógica do uso das TIC's no turismo.

A utilização constante de material impresso constitui alguns empecilhos, a saber: desatualização das informações contidas nos impressos, dispêndio de tempo e, principalmente, aumento nos custos com a impressão. Neste sentido, Bettoni (2009, p. 72-73) afirma que "A tecnologia da informação surge da estrutura da computação, comunicação e eletrônica, como carac- 
terística universal do turismo, transportando informações quase que instantaneamente para todo o mundo". Desse modo, as TIC's mais uma vez atuam e ganham notoriedade, não ligados diretamente ao turista, mas agora às empresas de turismo.

Corrêa (2010, p. 89) aborda o uso das redes sociais enquanto estrutura virtual ligada ao turismo, segundo a autora "A ausência de restrições físicas e temporais pode ser um dos fatores que contribui para o sucesso das plataformas de redes sociais”. Do mesmo modo, Cacho e Azevedo (2010) destacam que na sociedade atual "[...] torna-se cada vez mais urgente o uso das novas fontes de informação como veículo difusor dos serviços e informações turísticas". Com isso, o surgimento e o aperfeiçoamento de sites, portais e outros canais informativos que utilizam a Internet, como os aplicativos nos smartphones e tablets, possibilitou maior interação com outros usuários da rede, como também uma forma segura e eficaz de busca de dados sobre o destino pesquisado, de forma rápida e atualizada.

Moraes (2007, p. 167) discorre sobre a relação social intermediada pelos meios tecnológicos, para ela a "relação entre o global e o local é uma característica da globalização que vem sendo acentuada pela Tecnologia da Informação, promovendo a integração de pessoas e de culturas através de serviços como a internet, telefonia e televisão". Além disso, essa integração promove uma série de inserções e compartilhamentos culturais, perfazendo a ideia de um tour virtual, tão comum nos dias atuais. Nesse sentido, o site Terra (2013) aponta que o Google, através da tecnologia do Street View, realizou um projeto piloto no ano de 2013 com vistas a mapear as igrejas católicas históricas da cidade de São Paulo, a começar pela Catedral da Sé e pela Igreja da Consolação, iniciando um processo virtual de visitação e experimento turístico.

Moraes (2007, p. 168) destaca que "A introdução de novas tecnologias de informação nas organizações ampliou as potencialidades da informação como recurso estratégico [...]". Esse posicionamento recai sobre a intensiva utilização da Internet por infinitos meios, facilitando a vida dos usuários, diminuindo custos e tempo, embora o contato pessoal (físico) fique, substancialmente, suprimido.

Mais ainda, pode-se dizer que a sociedade atual é dependente dos mais diferentes recursos tecnológicos existentes, o que dinamiza suas atividades e proporciona menos gasto de tempo e de locomoção. Por sua vez, otimiza a busca por dados e informações sobre determinados lugares, destinações 
e atrativos turísticos, tendo papel relevante na cadeia de execução e consumo do turismo.

Atualmente os aplicativos multiplicam-se com uma velocidade e uma variedade enorme, abrindo caminho para novas experiências no turismo. Um dos bons exemplos vem do MTUR depois de desenvolver, em junho do mesmo ano, o Fellow Trip, aplicativo que auxilia o turista a criar roteiros pelo Brasil. Inicialmente, quem baixar o aplicativo terá acesso a uma ferramenta semelhante à de um "parceiro de viagem", como bem coloca o site da instituição. O uso é interativo e faz com que o turista seja auto guiado pelas informações contidas no Fellow Trip, advindas dos usuários que avaliam roteiros turísticos, restaurantes, hotéis, entre outros. As informações são repassadas pelos usuários, tornando a interação um processo de facilitação e sucesso para a estadia do visitante, embora informações errôneas possam prejudica-los (MTUR, 2014).

Seguindo este exemplo, a Secretaria de Turismo do estado do Rio de Janeiro, no ano de 2012, lançou o Rio Wonders, outro aplicativo criado para facilitar a estadia do turista. Trata-se de um aplicativo que disponibiliza ao usuário um guia turístico completo da cidade do Rio de Janeiro e dos arredores (RIO DE JANEIRO, 2012). No geral, o guia digital surge como mais uma ferramenta disponível em um dispositivo móvel, garantindo de forma ágil, rápida e segura aos viajantes e moradores, informações confiáveis que mostram uma lista de indicações disponíveis na destinação.

\section{APLICATIVOS E SUA RELAÇÃO COM O TURISMO}

O primeiro modelo de smartphones a rodar aplicativos foi apresentado, em 2007, pelo então presidente da Apple, Steve Jobs, morto em 2011. Inovador e multifuncional, à época, o iPhone revolucionou o mercado de celulares e potencializou o uso destas pequenas máquinas a fim de facilitar a vida de milhões de pessoas por meio da interação proposta pelos aplicativos.

De acordo com o Tech Tudo (2013) - site especializado em assuntos ligados à tecnologia -, o modelo da Apple fora lançado oficialmente em og de janeiro de 2007 e posto à venda em 29 de junho do mesmo ano. Quando surgiu, o aparelho era uma incógnita: dimensões maiores que as dos celulares à venda no mercado, câmera de foto e vídeo mais avançada, acelerômetro e, tela sensível ao toque, a grande novidade do aparelho. Estas características inusitadas, mas agradáveis, fez com que longas filas fossem formadas para 
a aquisição do dispositivo nas lojas.

Outro site especializado em tecnologia, o Olhar Digital (2013), destaca o uso dos sistemas operacionais pelos smartphones e tablets. Os aparelhos da Apple rodam com um sistema operacional próprio, o iOS. Para não ficarem de fora desse mercado, outras grandes fabricantes passaram a desenvolver sistemas operacionais para os seus aparelhos. Essa corrida tecnológica fez com o Google lançasse em 2008 o sistema operacional Android, onde, cinco anos mais tarde seria utilizado por cerca de $80 \%$ dos smartphones em todo o mundo, comprovando sua fácil adaptação e execução às diversas plataformas físicas de fabricantes de celulares, como a Samsung, LG e a Motorola.

Essa revolução no mercado de telefonia móvel junto à ampliação e ao desenvolvimento de aplicativos passou a ser prioridade dos engenheiros e programadores de softwares, confirmando a tendência mundial iniciada pela Apple com o iOS e com o Google, por meio do Android. Atualmente existem outros sistemas operacionais, como o Windows Phone desenvolvido pela Microsoft e a plataforma independente Java, menos utilizada. Ao passo que o número de usuários de smartphones crescia, aumentava também a diversidade dos aplicativos. Dados disponibilizados no site Olhar Digital (2012) dão conta de que no ano de 2012 a App Store possuía mais de 500 mil aplicativos para download, o Google Play cerca de 400 mil e a Marketplace do Windows Phone, apenas 70 mil.

No desenvolver de todo esse movimento tecnológico, o aplicativo de celular se tornou uma ferramenta comum e indispensável para uso nos mais diversos setores da economia, um deles é o de lazer e turismo (NUNES; MAYER, 2009). Neste sentido, uma infinidade de aplicativos é criada para os mais diferentes fins e demandas: divulgação de eventos, localização de atrativos, tours virtuais, chamada de táxis, localização de restaurantes, entre outros.

No entendimento de Farias et al. (2013, p. 2), "A mídia no turismo tem grande importância, pois sua função é trabalhar o imaginário do público alvo para que ocorra a ação". Assim, o desenvolvimento midiático possui fundamental e expressiva atuação sobre as ações envolvendo o turismo. Numa concepção geral, não há mais como pensar no turismo sem a presença da tecnologia para o seu aperfeiçoamento, execução e consumo.

Por essa necessidade, são criadas ferramentas tecnológicas que subsidiam e inovam as funções no setor de turismo, possibilitando mecanismos de adaptação às novas interações propostas pela atividade, adicionadas por meio do incremento de tecnologia aos produtos e serviços do turismo. 
Nesta perspectiva, surge o aplicativo Clube Zoom - objeto de estudo. Criado em abril do corrente ano pelo administrador com Master of Business Administration (MBA) e concentração na área de marketing e propaganda, Santiago Melo Soares. A facilidade para o desenvolvimento do aplicativo se deu porque Soares trabalha com informática há bastante tempo, especializando-se na criação de softwares.

Soares conta como surgiu a ideia de criar o Clube Zoom:

A ideia veio após observar que surgiram várias opções [de entretenimento] nos últimos quatro anos aqui em Parnaíba, sendo escassamente divulgados nas redes sociais de forma descentralizada, sem sistematização e sem uma formato apropriado para usuários de tecnologia móvel que enfrentam uma avalanche de informações e conexões móveis de baixíssima velocidade. Desenvolvemos o aplicativo para resumir a busca por entretenimento em apenas 3 cliques.

Continuando a entrevista, um dos questionamentos feitos à Soares buscava identificar o público-alvo que o Clube Zoom queria atingir:

[...] Lançamos o aplicativo com um formato básico, pois não saberíamos qual seria a resposta do público e quais seriam suas exigências. $\mathrm{O}$ aplicativo foi lançado com pouca divulgação e em 8 meses já obteve mais de 500 downloads e muitas sugestões. Como o Clube Zoom é o pioneiro no Piauí neste segmento, vimos a oportunidade de levá-lo a outras cidades. A nova versão possui muitas novidades e será testada em meados de Dezembro de 2014 com previsão de lançamento em Janeiro de 2015.

Dutra (2013, p.16) traz uma concepção acerca do uso demasiado da Internet por dispositivos móveis, para o autor a tendência são os “[...] celulares ou aqueles que possuem uma plataforma mais adequada a receber o conteúdo gerado da web, que são chamados de smartphones". Ainda segundo Dutra (ibid.), a configuração e a evolução dos produtos tornará "O acesso [...] rápido, objetivo e dinâmico com os mais diversos fatores e serviços que algo pode proporcionar". Isso, certamente, contribui para a oferta de aplicativos cada vez mais funcionais e dinâmicos, pondo fim a diversos problemas enfrentados pela sociedade e que podem ser resolvidos mediante consulta a aplicativos, como: pagamentos de contas; compra de passagens e pacotes de viagens; acesso à programação de bares, shows, cinemas, teatros, entre outros. Este último recurso é encontrado no Clube Zoom. 
Quanto à rapidez no acesso à Internet descrito por Dutra (2013), este parece ser o maior empecilho para quem desenvolve aplicativos no Brasil, sendo, também, o principal problema relatado por Soares:

Por conta de algumas limitações que a plataforma tem [...] g gente tem que estudar todo o aspecto de transmissão de dados porque a nossa Internet é lenta [...] e quando vai pro interior é mais lento ainda, pra outras cidades vizinhas de porte menor, se torna bem mais lento... Então a gente tem essa preocupação de manter o aplicativo leve, elegante, mas também funcional.

Visando minimizar esta deficiência, Soares argumenta:

Isso é um ponto que depende da operadora, mas na próxima versão que for vir, será totalmente diferente da que é hoje. A gente tá vendo uma forma dele (o aplicativo) baixar a programação pro aparelho pra poder ser acessado off line. Então, isso já vai tornar a aplicação mais rápida, já vai ficar off line (armazenada) no aparelho.

Com propostas parecidas às do Clube Zoom, muitos outros aplicativos existem no país, visando tornar mais fácil a estadia do turista, como também a interação com os moradores da destinação visitada. $O$ Vibezone é um deles e seu funcionamento está condicionado ao uso do Global Positioning System (GPS), visto que seu objetivo primordial é informar ao usuário onde estão localizados os eventos mais "badalados", os que estão "bombando" no exato momento do acesso e os locais mais próximos para lazer e entretenimento do usuário. Tudo isso é realizado em tempo real, proporcionado pela interação direta dos usuários através do check-in feito pelos respectivos dispositivos móveis (ITUNES, 2014).

Nesta perspectiva, Foster (2011, apud FARIAS et al, 2013) lembra os avanços provocados pelas novas mídias na atualidade. Sob esta visão, o autor coloca que a interação evidente entre o emissor e o receptor torna mais subjetiva a comunicação, ao passo que oferece mais recursos e possibilidades de informações, tendo o feedback como o principal aliado dessas novas mídias. Para isso, o autor acrescenta que as novas mídias são carregadas de tecnologia, a saber: grande capacidade de processamento de dados, acesso à Internet, GPS, câmera, entre outros, tornando mais real a interatividade e a funcionalidade dos dispositivos.

O dimensionamento da Internet relacionado ao turismo contribui, não apenas para a diminuição dos custos motivada pela desintermediação das 
agências, mas por oferecer aos viajantes informações mais condizentes com a realidade do mercado. Corroboram com esta afirmação as pesquisadoras Flecha e Da Costa (2004), para elas a Internet configura-se com uma das mais adequadas ferramentas tecnológicas para difusão de informações sobre serviços turísticos de modo direto e rápido ao internauta. Nos dizeres de Quevedo (2007), com o uso da Internet os turistas obtêm informações acerca das destinações turísticas antes mesmo de sair da localidade emissora, possibilitando a organização do próprio roteiro turístico, embora possa causar efeitos negativos quanto à geração de empregos no destino.

Neste mesmo cenário, Farias et al. (2013, p. 2) cita um recente estudo feito pela Travel Tech Consulting - consultoria americana relacionada à tecnologia -, onde diz: "Esse indivíduo (o turista) consome a nova mídia dos dispositivos móveis antes, durante e depois da experiência turística, conhecendo e compartilhando essa experiência através desses dispositivos". Com isso, comprova uma tendência percebida mundialmente, o viajante está sempre conectado.

O MTUR foi mais além ao lançar a versão portátil do Guia Turismo Acessível, já presente em sítio da Internet (http://www.turismoacessivel.gov.br). A versão, adaptada para smartphones e tablets com acesso à Internet, contém informações de mais de 530 mil estabelecimentos no Brasil. Através do aplicativo, os usuários tem conhecimento acerca da existência de rampas, menus em braile, banheiros adaptados e piso tátil, como informa a descrição dada pelo órgão federal. De acordo com o presidente do MTUR, Vinícius Lages, o "aplicativo está ao alcance das mãos e, por esta razão, poderá ser usado durante a experiência turística, em tempo real” (MTUR, 2014), otimizando o processo de execução da atividade pelos Portadores de Necessidades Especiais (PNE), gerando inclusão social.

\section{PROCEDIMENTOS METODOLÓGICOS}

O aporte teórico-metodológico que compõe este trabalho partiu da pesquisa quantitativa e exploratória, além de uma entrevista. Soma-se ainda a pesquisa bibliográfica e documental, a fim de elaborar parte do material pertinente à fundamentação teórica. Por se tratar de um trabalho que o objeto de estudo é um aplicativo para smartphones e tablets, completou os métodos e técnicas o acesso a sites da Internet, embora não sejam de natureza científica, foram utilizados por apresentarem dados e informações condizentes à realidade dos acontecimentos. 
Para compreender o aplicativo Clube Zoom enquanto objeto de estudo, utilizou-se a pesquisa exploratória para tais fins, haja vista a ausência de informações sobre o supracitado aplicativo. Segundo Gil (2008, p. 27) “As pesquisas exploratórias são desenvolvidas com o objetivo de proporcionar visão geral, de tipo aproximativo, acerca de determinado fato" e, complementa, afirmando que esse tipo de pesquisa, geralmente, "[...] é realizado especialmente quando o tema escolhido é pouco explorado e torna-se difícil sobre ele formular hipóteses precisas e operacionais" (ibid.). Afirma, ainda, que "[...] as pesquisas exploratórias constituem a primeira parte etapa de uma investigação mais ampla” (ibid.).

A pesquisa documental, de acordo com Lakatos e Marconi (2003, p. 174) tem como característica principal a fonte de coleta de dados, estando "[...] restrita a documentos escritos ou não, constituindo o que se denomina de fontes primárias", podendo ser adquiridas no momento em que o fato ou fenômeno ocorrem, ou seja, de modo instantâneo, constituindo-se como uma técnica de fontes primárias.

Quanto à pesquisa bibliográfica, Lakatos e Marconi (2003, p. 183) reforçam:

A pesquisa bibliográfica, ou de fontes secundárias, abrange toda bibliografia já tornada pública em relação ao tema de estudo, desde publicações avulsas, boletins, jornais, revistas, livros, pesquisas, monografias, teses, material cartográfico etc., até meios de comunicação orais: rádio, gravações em fita magnética e audiovisuais: filmes e televisão.

A entrevista do tipo padronizada ou estruturada foi realizada com o desenvolvedor do aplicativo Clube Zoom, o administrador com concentração na área de marketing e propaganda, Santiago Melo Soares. A entrevista aconteceu na tarde do dia 28 de junho do corrente ano, sendo o áudio captado através de um aplicativo instalado no smartphone do entrevistador. $\mathrm{Na}$ concepção de Lakatos e Marconi (2003, p. 195), "A entrevista é um encontro entre duas pessoas, a fim de que uma delas obtenha informações a respeito de determinado assunto, mediante uma conversação de natureza profissional". Quanto ao tipo da entrevista, padronizada ou estruturada, esta acontece quando "[...] o entrevistador segue um roteiro previamente estabelecido; as perguntas feitas ao indivíduo são pré-determinadas" (ibid., p. 197). Na prática "Ela se realiza de acordo com um formulário elaborado e é efetuada de preferência com pessoas selecionadas de acordo com um plano" (ibid.). 
O procedimento de pesquisa partiu da elaboração de um questionário contendo 15 perguntas, sendo: 07 questões fechadas com duas alternativas ("sim" e "não"); 01 questão fechada com três opções de resposta; 05 questões fechadas com cinco variáveis de respostas; e, 02 questionamentos abertos. O formulário permaneceu disponível na versão on line no Google Docs no período de 29 de junho até 15 de julho, período escolhido aleatoriamente para aplicação dos questionários, dos quais 30 indivíduos responderam. Richardson (1989) caracteriza este método pelo emprego da quantificação, seja pela modalidade de coleta de informações, quanto no tratamento delas pelo uso de técnicas estatísticas. Destarte, Richardson (1989) afirma que o método possui como diferencial a garantia de precisão dos trabalhos realizados, conduzindo a resultados com reduzida chance de distorções.

\section{RESULTADOS E DISCUSSÃO DOS DADOS}

Lakatos e Marconi (2003) afirmam que para obtenção de informações e conhecimentos acerca de determinado problema, faz-se necessário a aplicação de questionários. Com isso, obtêm-se respostas ou hipóteses de algo que se queira por à prova. Desse modo, surge a pesquisa que engloba e dá base às avaliações propostas deste trabalho.

A princípio, a pesquisa visa analisar e avaliar o aplicativo Clube Zoom pelos usuários. Assim, 30 indivíduos responderam ao questionário on line, por meio do Google Docs. O link que direciona ao questionário esteve disponível no grupo "Bacharelado em Turismo - UFPI PHB" com endereço no Facebook (https://www.facebook.com/groups/266047406846103/) entre os dias 29 de junho e 15 de julho do corrente ano. Até a data final, o grupo continha 695 membros.

Os primeiros resultados apontam que $90 \%$ dos entrevistados conhecem ou ouviram falar do aplicativo Clube Zoom. Quando indagados se haviam baixado/instalado o aplicativo, 70\% afirmaram "sim". O Clube Zoom possui configuração e manuseio fácil e simplificado para $80 \%$ deles, os quais confirmaram saber utilizar as funções do aplicativo (Gráfico 1). 


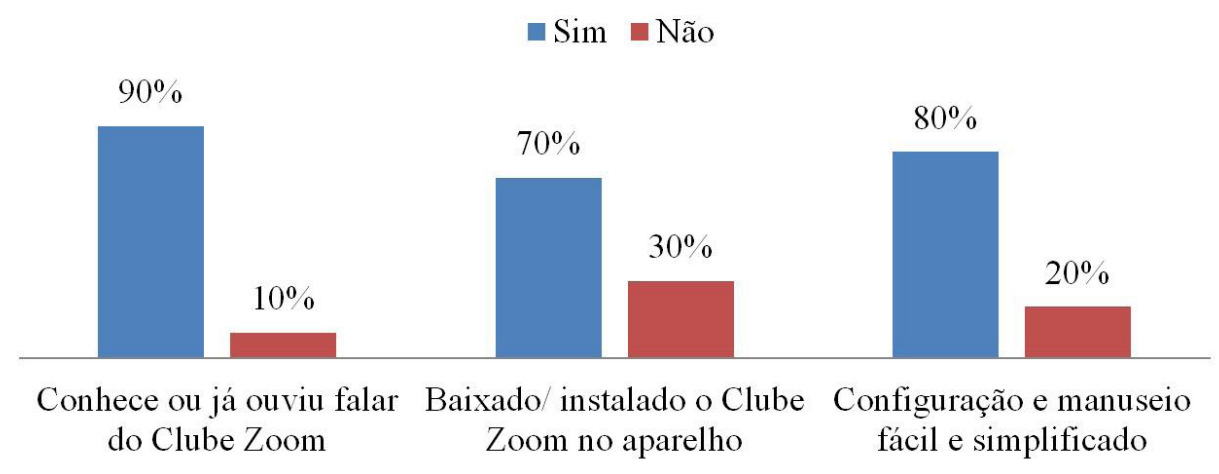

Gráfico 1 - Avaliações acerca do Clube Zoom pelos usuários.

Fonte: PESQUISA DIRETA (2014).

O caráter simplista do Clube Zoom, segundo Soares, está condicionado à baixa qualidade da transmissão de dados por parte das operadoras de telefonia móvel no município de Parnaíba, tornando deficiente o desempenho do aplicativo.

Àqueles que haviam baixado/instalado o Clube Zoom em seus dispositivos, 90\% responderam "sim" quando questionados se fazem uso regular do aplicativo, de acordo com os objetivos propostos (Gráfico 2). Neste cenário, projeta-se a afirmação de Buhalis (1998 apud LUCCA FILHO, 2005, p. 32), onde diz que "a informação é vital para a indústria do turismo". Bjerg, Larrea e Pachiana (2012, p. 4) dizem que as TIC's, relacionadas ao turismo e lazer, criam mecanismos que "Permiten construir un espacio de interacción simbólica donde el acceso al conocimiento presenta un alcance multisensorial e interactivo". Assim, o mundo globalizado é um grande consumidor de informações por meio da tecnologia, fazendo inovar e oferecer diversas opções aos consumidores, notadamente, os de serviços turísticos, os quais requerem dispêndios maiores de informações do local visitado.

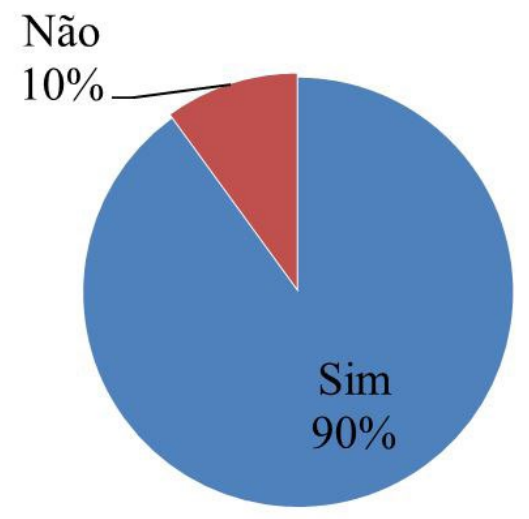

Gráfico 2 - Uso regular do Clube Zoom pelos usuários.

Fonte: PESQUISA DIRETA (2014). 
Tomando por base o modelo de escala de concordância de cinco pontos do tipo Likert, foram avaliados os níveis de maior aceitação e recusa do Clube Zoom por parte dos usuários. O quesito "utilização de imagens" obteve o maior grau de concordância com 43\% dos entrevistados respondendo "ótimo". O quesito "interface" recebeu o maior grau de discordância, ficando com $17 \%$ das indicações (Tabela 1).

Tabela 1 - Avaliação funcional do Clube Zoom por parte dos usuários.

\begin{tabular}{|c|c|c|c|c|c|}
\hline \multirow{2}{*}{ Acesso ao Clube Zoom } & Ótimo & Bom & Regular & Ruim & Péssimo \\
\hline & $23 \%$ & $70 \%$ & $7 \%$ & $0 \%$ & $0 \%$ \\
\hline \multirow{2}{*}{ Interface do Clube Zoom } & Ótimo & Bom & Regular & Ruim & Péssimo \\
\hline & $13 \%$ & $70 \%$ & $17 \%$ & $0 \%$ & $0 \%$ \\
\hline \multirow{2}{*}{$\begin{array}{l}\text { Utilizar imagens } \\
\text { no Clube Zoom }\end{array}$} & Ótimo & Bom & Regular & Ruim & Péssimo \\
\hline & $43 \%$ & $47 \%$ & $10 \%$ & $0 \%$ & $0 \%$ \\
\hline \multirow{2}{*}{$\begin{array}{l}\text { Interatividade entre usuário e desenvolvedor } \\
\text { do Clube Zoom }\end{array}$} & Ótimo & Bom & Regular & Ruim & Péssimo \\
\hline & $21 \%$ & $72 \%$ & $7 \%$ & $0 \%$ & $0 \%$ \\
\hline \multirow{2}{*}{ Avaliação geral do Clube Zoom } & Ótimo & Bom & Regular & Ruim & Péssimo \\
\hline & $24 \%$ & $72 \%$ & $3 \%$ & $0 \%$ & $0 \%$ \\
\hline
\end{tabular}

Fonte: PESQUISA DIRETA (2014).

Vale ressaltar que os pontos "ruim" e "péssimo" não foram sinalizados. Isso remete, basicamente, a dois aspectos: o aplicativo Clube Zoom satisfaz os usuários ao oferecer uma configuração básica, mas objetiva quanto à sua proposta; e, por ser leve e fácil de utilizar, fideliza os usuários carentes por informações precisas acerca da programação dos eventos locais. Ações executadas pelo Clube Zoom de forma regular e com confiabilidade, como atestam 100\% dos entrevistados (PESQUISA DIRETA, 2014).

Neste sentindo, O'Connor (2001) atenta que a atividade turística é cada vez mais dependente do fornecimento de informações, sendo elas o nutriente básico à efetivação e ao consumo da atividade. No entanto, para Middleton (2002 apud LUCCA FILHO, 2005), a Internet possibilita a adaptação dos clientes em relação à busca de informações nas empresas, se tornando uma premissa aos negócios do futuro, almejando cifras significativas de inserção pela web através das TIC's.

Outras análises advêm das perguntas abertas contidas no questionário. Nelas os entrevistados expuseram de forma subjetiva o seu ponto de vista acerca do Clube Zoom. Uns sugerem a inclusão de botões de compartilhamento direcionando-os às redes sociais como Facebook e Twitter, a fim de 
que seus amigos possam saber onde estão e a sua localização. Outros sugerem maior detalhamento dos estabelecimentos que promovem eventos, como: preços, público alvo, aceitação de cartões de crédito, cardápios, entre outros. É relevante mencionar que essas subjeções estarão disponíveis na versão a ser lançada no ano de 2015, exclusivo para os patrocinadores, como declarou Soares.

Nota-se, com isso, a importância do feed back para o aperfeiçoamento do aplicativo, feito através das opiniões, críticas, reclamações e sugestões dos usuários. Segundo Soares, a interatividade dos usuários acontece com frequência. De acordo com o relatório de Soares, 90\% são “elogios” e, muitos deles, acompanhados por sugestões que, depois de analisadas, fazem parte de uma lista de melhorias para o aplicativo.

Relacionando ao turismo, um entrevistado descreve a importância do Clube Zoom e de outros aplicativos análogos para o setor:

App's semelhantes são de grande importância ao turista, pois utiliza informações precisas e detalhadas sem o intermédio, muitas das vezes falso, de pessoas que não conhecem a fundo a programação de eventos da cidade naquele momento.

Ignarra (2001) demonstra preocupação nos serviços básicos disponíveis numa destinação turística, desde a infraestrutura essencial (fornecimento de água, transporte, saúde, energia elétrica) até serviços de comunicação. Estas ferramentas possibilitam aos turistas informações acerca do destino receptor: horários e itinerários das linhas de transporte públicos, localização de estabelecimentos comerciais, calendário de eventos, entre outros. Estes serviços fazem parte da hospitalidade do lugar, podendo prolongar a estadia do visitante.

Na perspectiva de Middleton (2002 apud LUCCA FILHO, 2005, p. 32) o turismo é "um mercado totalmente baseado no fornecimento de informações". Assim, confere uma responsabilidade dos agentes públicos e privados na oferta dos meios tecnológicos de acesso à comunicação e à informação, providos por dispositivos móveis como tablets e smartphones. Este processo é capitaneado pela Internet, como indica Devis-Botella (2010 apud CUADRA; MORALES; AGÜERA, 2014, p. 2):

[...] la importancia de internet para el sector turístico es evidente, ya que gracias a esta novedosa herramienta, cualquier usuario puede decidir el destino final sin necesidad de acudir a intermediarios 
físicos, cambiando la tendencia y ganando en importancia los recursos electrónicos a la hora de la conformación y planificación del viaje.

Então, faz-se necessário o uso intensivo da tecnologia direcionada ao setor de turismo, visando não somente facilitar a vida do turista, mas reduzir tempo e custos, elevando a satisfação do visitante no destino receptor por meio da hospitalidade que lhe é fornecida através dos aplicativos e softwares, cada vez mais difundidos e aperfeiçoados à realidade.

Neste cenário, Soares destaca o objetivo principal e as pretensões do Clube Zoom, frente à interatividade e ao desempenho, respectivamente:

O principal objetivo do Clube Zoom é resumir as buscas em inúmeros canais das redes sociais em apenas três cliques no aplicativo, tendo como meta a implantação de novos recursos (como imagens e interatividade) preocupando-se em manter a plataforma leve. Seu principal diferencial dos aplicativos similares à nível nacional é ser uma plataforma leve e capaz de trafegar em redes lentas.

A partir disso, o Clube Zoom assume um papel relevante no tocante aos meios de comunicação e informação do turismo e lazer em Parnaíba, visto sua proposta original e suas formas democráticas de atuação, conferindo êxito às ações desempenhadas e iniciando um processo de guiamento turístico digital de modo democrático e inclusivo.

\section{CONSIDERAÇÕES}

O trabalho tratou do uso de aplicativos e demais recursos tecnológicos por meio de ferramentas móveis: tablets e smartphones. O uso, propriamente dito, faz relação ao setor de turismo e sua contribuição aos viajantes, embora os residentes também sejam beneficiados com os avanços da tecnologia aplicada ao lazer e entretenimento. Este uso do Clube Zoom faz alusão às funções contidas no aplicativo, dando destaque à programação de bares, casas de shows, cinemas, teatros, entre outros, onde num contexto geral, dá base aos usuários que disporão de um canal informativo gratuito e móvel, capaz de ser utilizado em qualquer local, condicionado à existência de Internet no dispositivo.

No setor de turismo, aplicativos de propostas similares, mas com serviços e funções um tanto quanto distintas, são apreciados e utilizados pelos usuários de dispositivos móveis como verdadeiros guias turísticos digitais. 
Essa intensificação se deu com a popularização destes equipamentos, cada vez mais presente nas mais diversas classes de consumo, não sendo restrito apenas às classes média e alta.

Na cidade de Parnaíba, percebe-se a dificuldade de obtenção de informações acerca dos atrativos e opções de lazer noturno. A partir disso, o aplicativo Clube Zoom mostra-se eficiente e necessário para a otimização e oferta de conteúdo turístico e de entretenimento, contribuindo e melhorando a estadia do visitante e, sobretudo, do morador.

Do exposto, conclui-se que o aplicativo Clube Zoom é eficaz em seus objetivos, provando ser uma ferramenta útil e de grande valia aos usuários. Vale ressaltar as inúmeras melhorias incorporadas com as adições propostas nas atualizações, as quais são subsidiadas pelo intermédio dos usuários, a fim de tornar mais completo o aplicativo.

\section{REFERÊNCIAS}

BETTONI, Eduardo Michelotti. A colaboração dos usuários na divulgação de destinos turísticos baseada no compartilhamento de dados geoprocessados. Turismo \& Sociedade. v.2, n.1, p. 64-89. 2009.

$\mathrm{BIZ}$, Alexandre Augusto. Avaliação dos portais turísticos governamentais quanto ao suporte à gestão do conhecimento. Tese (doutorado) 240 fls. Programa de Pós-Graduação em Engenharia e Gestão do Conhecimento, Universidade Federal de Santa Catarina (UFSC): Florianópolis, 2009.

BJERG, Lilian A; LARREA, Martín; PACHIANA, Gabriel. TIC y su Integración de la realidade virtual como herramienta para la educación y el turismo. El caso de la Fortaleza Protectora Argentina (Bahía Blanca, Argentina). $5^{\circ}$ Congresso Latino-Americano de Investigação Turística. São Paulo, 2012.

BRASIL. Ministério do Turismo (MTUR). Embratur lança guia de viagem interativo. 2014. Disponível em: <http://www.turismo.gov.br/turismo/noticias/todas_noticias/20140605_7. html> Acesso em: 04 dez. 2014.

. Turismo lança aplicativo de turismo acessível. 2014. Disponível em:

<http://www.turismo.gov.br/turismo/noticias/todas_noticias/20141203_4.html> Acesso em: 09 dez. 2014.

CACHA, Andréa do Nascimento Barbosa; AZEVEDO, Francisco Fransualdo de. O turismo no contexto da sociedade informacional. Revista Brasileira de Pesquisa em Turismo. v.4, n.2, p. 31-48, ago. 2010.

CORRÊA, Cynthia Harumy Watanabe. TAM Linhas Aéreas no Twitter: Canal de comunicação ou rede social? Revista Brasileira de Turismo. v.4, n.3, p.85-108, dez. 2010.

CRUZ, Vera Lúcia Lima da; MOTA, Karol Monteiro; PERINOTTO, André Riani Costa. Redes 
sociais na Internet: estratégia para divulgação das potencialidades turísticas do Piauí Brasil. Revista Rosa dos Ventos. 4(I), p. 77-88, jan-jun, 2012.

CUADRA, Salvador Moral; MORALES, Pablo Cañero; AGÜERA, Francisco Orgaz. Reputación online, redes sociales y turismo. Um estudio de caso en Andalucía. TURyDES - Revista de investigación em turismo y desarrollo local. v.7, n.16, jun-jul, 2014.

DUTRA, Felipe Nascimento. Guia Turístico de Porto Alegre para Copa 2014: Aplicativo Mobile iOS. Monografia, 91 fls. Centro Universitário Ritter dos Reis (UniRitter), Curso de Design Gráfico. Porto Alegre, 2013.

FARIAS, Athur; CRUZ, Caio de Godoy Vaz; RAMOS, Écila; BELÉM, Jonnhy; SOUZA, Lorena; MORISSON, Alcir de. Comunicação interativa: aplicativo para dispositivos móveis voltados ao turismo em Belém do Pará. XX Prêmio Expocom 2013 - Exposição da Pesquisa Experimental em Comunicação. Disponível em: < http://portalintercom.org.br/anais/norte2013/expocom/EX34-0356-1.pdf> Acesso em: 09 dez. 2014.

FLECHA, Ângela Cabral; DA COSTA, Jane Lara Pereira. O impacto das novas tecnologias nos canais de distribuição turística: um estudo de caso em agências de viagens. Caderno Virtual de Turismo. v.4, n.4, p. 44-56, 2004.

GIL, Antonio Carlos. Métodos e técnicas de pesquisa social. 6. ed. São Paulo: Atlas, 2008. IGNARRA, Luiz Renato. Fundamentos do turismo. São Paulo: Pioneira Thonsom, 2001.

ITUNES. Vibezone - Explore o mundo ao seu redor em tempo real. 2014. Disponível em:<https://itunes.apple.com/us/app/vibezone-explore-world-around/id815723069?l$\mathrm{s}=1 \& \mathrm{~m}$ $t=8>$ Acesso em: 05 jul. 2014 .

LAKATOS, Eva Maria; MARCONI, Marina de Andrade. Fundamentos de metodologia científica. 5. ed. São Paulo: Atlas, 2003.

LUCCA FILHO, Vinicius de. Estudo do fluxo de informações em centros de informações turísticas de Santa Catarina: Programa Portais do Lazer. Dissertação (Mestrado) 134 fls. Programa de Pós-Graduação em Ciência da Informação. Universidade Federal de Santa Catarina (UFSC). Florianópolis, 2005.

MORAES, Adriana Gomes de. Tecnologia de informação nas agências de turismo: uma análise de como as agências estão utilizando esse recurso para se manter competitiva.

Revista de Turismo y Patrimônio Cultural. v.5, n.2, p. 163-173, 2007.

NUNES, Marcelo de Oliveira; MAYER, Verônica Feder. Aceitação tecnológica pelo turista no espaço natural: utilidade, compatibilidade e intenção de uso de um aplicativo em Ilha Grande/RJ. $5^{\circ}$ Congresso Latino-Americano de Investigação Turística. São Paulo, 2012.

O'CONNOR, Peter. Distribuição da informação eletrônica em turismo e hotelaria. Porto Alegre: Bookman, 2001.

OLHAR DIGITAL. Android, iOS e Windows Phone: conheça as diferenças entre eles! 2012. Disponível em: <http://olhardigital.uol.com.br/video/android,-ios-e-windows-phone-conhecas-as-diferencas-e-escolha-o-seu/25525> Acesso em: 04 jul. 2014. 
história. Disponível em: <http://olhardigital.uol.com.br/noticia/37760/37760> Acesso em: 04 jul. 2014.

PÉREZ, Xerardo Pereiro. Turismo Cultural. Uma visão antropológica. Tenerife, Espanha: ACA y PASSOS, 2009.

QUEVEDO, Mariana. Turismo na era do conhecimento. Florianópolis: Pandion, 2007.

RICHARDSON, Roberto Jarry. Pesquisa social: métodos e técnicas. São Paulo: Atlas, 1989.

RIO DE JANEIRO. Secretaria de Turismo lança aplicativo com guia do Rio de Janeiro. 2012. Disponível em: <http://www.rj.gov.br/web/imprensa/exibeconteudo?article-id=1010851> Acesso em: 04 dez. 2014.

SILVA, Danilo Serafim da; MENDES FILHO, Luiz. Uma análise preliminar do uso de comentários na Internet na escolha de um destino de viagem. Turismo: Estudos \& Práticas. V.2, n.2, p. 174-195, 2013.

TECH TUDO. iPhone completa 6 anos: relembre o primeiro modelo e veja a evolução. 2013. Disponível em: <http://www.techtudo.com.br/artigos/noticia/2013/06/iphon e-completa-6-anos-relembre-o-primeiro-modelo-e-veja-evolucao.html> Acesso em: 04 jul. 2014.

TERRA. Google fotografa igrejas de São Paulo para criar visita virtual. 2013. Disponível em: <http://tecnologia.terra.com.br/internet/google-fotografa-igrejas-de-sao-paulo-para-criar-visita-virtual,885c1ddd313ae310VgnVCM4000009bcceboaRCRD.html> Acesso em: 03 jul. 2014.

TRIGO, Luiz Gonzaga Godoi Trigo. A sociedade pós-industrial e o profissional em turismo. 4. ed. Campinas, SP: Papirus, 2000. 


\section{José Maria Alves da Cunha}

Graduando do curso de Bacharelado em Turismo pela Universidade Federal do Piauí (UFPI). Estagiário do Grupo de Estudos e Pesquisas Interdisciplinar em Turismo (EITUR).

\section{José Geraldo da Silveira Júnior}

Graduando do curso de Bacharelado em Turismo pela Universidade Federal do Piauí (UFPI). Estagiário do Grupo de Estudos e Pesquisas Interdisciplinar em Turismo (EITUR).

\section{André Riani Costa Perinotto}

Doutor em Ciências da Comunicação - UNISINOS/RS. Mestre em Geografia pela Universidade Estadual Paulista - UNESP/ Rio Claro/SP. Especialista em Docência para Ensino Superior em Turismo e Hotelaria pelo SENAC/SP. Graduado em Bacharelado em Turismo pela Universidade Metodista de Piracicaba (UNIMEP). Professor Adjunto (D.E.) do Curso de Bacharelado em Turismo da Universidade Federal do Piauí (UFPI), Campus Ministro Reis Velloso. 
